\section{Accelerating threats to Cambodia's wildlife}

South-east Asia is at the epicentre of the Anthropocene extinction crisis (Duckworth et al., 2012, S.A.P.I.E.N.S., 5.2), and threats to the unique wildlife of the region are increasing (Hughes, 2017, Ecosphere, 8, e01624). The Wildlife Alliance has been implementing law enforcement and protected area management across $>5,000 \mathrm{~km}^{2}$ of Southern Cardamom National Park and Tatai Wildlife Sanctuary in the Cardamom Rainforest Landscape, south-west Cambodia, a globally significant landscape for conservation, since 2002 (Gray et al., 2016, Gajah, 45, 35-38). Since 2015 we have observed a significant increase in forest and wildlife crime in the landscape's protected areas. The number of illegal chainsaws confiscated by our rangers annually has increased by $650 \%$, and the number of hunting snares removed and destroyed annually has increased by $300 \%$, totalling 19,986 in 2018. Illegal land encroachment into the protected areas has increased by $750 \%$, from 24 ha annually during 2008-2010 to 180 ha in 2018. These trends are unlikely to be restricted to a single protected area and we believe they are driven by the recent Chinese investment in South-east Asia, part of China's national Belt and Road Initiative. An estimated USD 8 trillion worth of investment is planned across c. 120 countries (Huang et al., 2016, Chinese Economic Review, 40, 314-321). The Belt and Road Initiative has significant potential to impact biodiversity (Laurance et al., 2017, Science, 358, 442-444). Cambodia, a country in which China is the largest investor and to which it is increasingly politically aligned, is becoming a hub for capital investment and tourism from mainland China. This investment has been associated with landgrabbing and speculation, currently the most significant drivers of deforestation in Cambodia, as well as increased demand for illegal wildlife products. The newly developed coastal Sihanoukville Special Economic Zone, c. $70 \mathrm{~km}$ from the Tatai Wildlife Sanctuary, has $>100$ Chinese enterprises and companies, with a total investment of $>$ USD 3 billion (Vannarith, 2017, Khmer Times, 15 June 2017). This investment both increases the value of land, thus promoting land speculation and illegal deforestation, and stimulates demand for illegal wildlife and timber products. Responding to these accelerating threats is stretching law enforcement capacity and resources of both government and civil society. Without significant increases in funding for effective protected area management and law enforcement, significant future extirpations and extinctions will occur throughout South-east Asia.

THOMAS N.E. GRAY (๑ orcid.org/0000-0002-3642-4724)

Wildlife Alliance, New York, USA

E-mailgray@wildlifealliance.org

Suwanna Gauntlett Wildife Alliance, Phnom Penh, Cambodia 